\title{
TEMPERATURE AS THUMB RULE PREDICTOR OF OZONE LEVELS IN SANTIAGO DE CHILE GROUND AIR
}

\author{
RUBIO, MARÍA A. *, LISSI G. EDUARDO
}

\author{
Facultad de Química y Biología, Universidad Santiago de Chile, USACH, Av. L. B. O'Higgins 3363, Santiago, Chile. Centro Para el Desarrollo de la \\ Nanociencia y Nanotecnología (CEDENNA), Santiago 9170124, Chile.
}

\begin{abstract}
Ozone concentrations in the urban air of Santiago de Chile frequently surpass the air quality standard in summertime, particularly in the eastern part of the city (Las Condes). The main parameter that determines ozone episodes is the ground level daily maximum temperature. In the present work we propose that this single parameter can be employed as a simple predictor of the expected ozone levels. In particular, it is found that high ozone episodes takes place in Las Condes when the maximum daily temperature is higher than $30^{\circ} \mathrm{C}$. This single criterion applies during all the summer period (from December to March) and for weekdays and weekends. On the other hand, ozone episodes in downtown take place only when the maximum daily temperature reaches values higher than $32.5^{\circ} \mathrm{C}$. These simple relationships imply that weather forecast could be employed by the citizens to estimate the risk associated to carry out outdoors activities.
\end{abstract}

Keywords: tropospheric ozone; ozone forecast; air temperature; weekends; ozone episodes; Santiago de Chile.

\section{I . INTRODUCTION}

Presence of photochemical smog is a common feature of urban air in summer. It is characterized by high (diurnal) concentrations of secondary oxidants such as ozone and PAN ${ }^{1,2}$ that, together with other pollutants (such as aldehydes) are of concern due to their toxic potential. In particular, it has been established that ozone exposure must be minimized at concentrations ca. three times its natural background, in particular for persons with pulmonary and/or respiratory problems. This has lead to most countries to establish one or eight hours, maximum levels ${ }^{3,4}$ and to the recommendation of reducing outdoors exposure and activities to most vulnerable groups, such as children and old persons during high ozone concentration periods (ozone episodes). In this context it is useful to have predictors of "today", "tomorrow" and "next days" concentrations to alert the population. In this sense, the optimum predictor should be readily accessible and understood for the current citizens.

A large number of predictive models of different complexity have been developed and applied to a variety of ambient, including Santiago de Chile urban air. 5,6 Most of the models have shown that an important parameter conditioning ozone levels is the daily maximum temperature ${ }^{7,89}$ and that this simple parameter can, per se, be employed as ozone predictor. For example, Khoder ${ }^{10}$ reported, for an urban area in greater Cairo, a significantly positive correlation coefficient between ozone and temperature. Markovic ${ }^{11}$ reported that in the urban area of Belgrade, ozone concentrations higher than $90 \mathrm{ppbv}$ occurred at temperatures higher than $30^{\circ} \mathrm{C}$ and low wind speeds. Tarasova and Kurpetchko ${ }^{12}$ found that at Lovozero, located in Russian Tundra, a regression model of daily mean ozone concentrations on such parameters as temperature, relative humidity and wind speed explains up to $79 \%$ of day-to-day ozone variability. Khiem et al. ${ }^{13}$ applied a lineal regression to data obtained in the Central Kanto area with temperature and wind speed as independent variables and found higher ozone concentrations when the city acts as heat island. Vukovich and Sherwell ${ }^{14}$ found that, in the Baltimore-Washington corridor, historical data collected in summer during 15 years indicate that the main meteorological parameters determining ozone levels were temperature and sky cover. Abdul-Wahab and Al-Alawi ${ }^{15}$, using artificial neural networks establish that temperature played an important role, while solar radiation had a lower effect than expected. A neuronal network approach was used ${ }^{16}$ to explain high ozone values in greater Athens area, founding that temperature is the predominant factor and that neural models that use the air temperature as the only input parameter can provide remarkably accurate predictions. Lee et al. ${ }^{17}$ correlated the emergence of urban ozone episodes in autumn with air temperature rise in Hong Kong. Dueñas et al. ${ }^{18}$, from a regression model, concluded that in an urban area in the Mediterranean Coast, the main meteorological factor that determines ozone concentration is temperature, with humidity and wind speed playing lower roles. Rasmussen et al..$^{19}$ also discussed the surface ozone-temperature relationships in the eastern US. Im et al. ${ }^{20}$ modeled the impact of temperature changes on summer time ozone and its precursors in the Eastern Mediterranean. A similar study was carried out in South Texas ${ }^{21}$. The effect of urbanization, with its concomitant increase in heat island warming, was discussed by Cardalino and Chameides ${ }^{22}$. These authors found a positive correlation between temperature and ozone in Atlanta metropolitan area, concluding that most of the effect could be related to the large activation energy of PAN decomposition. All these studies highlight the close relationship between ozone levels and temperature. The aim of the present work is to establish if a simple parameter (maximum daily temperature) is a reasonable predictor of the occurrence of high ozone events during the current day, tomorrow and next days through a simple weather forecast of the daily maximum temperature. This would allow to the common citizen concluding if it is advisable to be engagedin "outdoors" activities. There have been several attempts to forecast ozone levels at Santiago, Chile. ${ }^{5}$ The structure of the forecasting model included a combination of persistence and daily maximum air temperature as input variables. Later on, the model was improved by taking only the rise in temperature as input variable and weekends and rainy days as interventions. The model consistently outperforms a pure persistence forecast. The authors concluded that the model could be used to warn people about the potential occurrence of episode days. However, it must be considered that this modeling is complex and the predicted episodes must be "read" by the authorities and afterward "transmitted" to the citizens. An ideal predictor should be

i) Easily understood by the population

ii) Valid for all the city,

iii) Valid for all periods of the year, and

iv) Valid for weekdays and weekends.

In the following sections we shall evaluate if, in Santiago, the maximum temperature is a single predictor of high ozone events that fulfils those requirementsI

\section{MATERIAL AND METHODS}

Ozone concentration ( 8 hours mobile average) and ground level temperatures (maximum and minimum daily values) were obtained daily from MACAM-2 network,

(Air Quality Monitoring Program in Santiago Metropolitan Area) operated by MMA

(Environmental Minister) during the months of December to March, starting on December 2008 and ending in March 2012 (561 days). Ozone was measured with a photometric ozone analyzer from Thermo Environmental Instruments, model 49i (LD $0.25 \mathrm{ppb} ; \pm 1 \%$ precision). Data were obtained at the sampling stations located in downtown Santiago, Parque O'Higgins (POH, UTM coordinates 345904E 6296352N) and in the east side of the city, Las Condes (LC, UTM coordinates 358363E 6306237N). Figure 1 shows the location of these stations. LC station was selected due to the high ozone concentrations traditionally measured in this part of Santiago's basing ${ }^{23}$ 


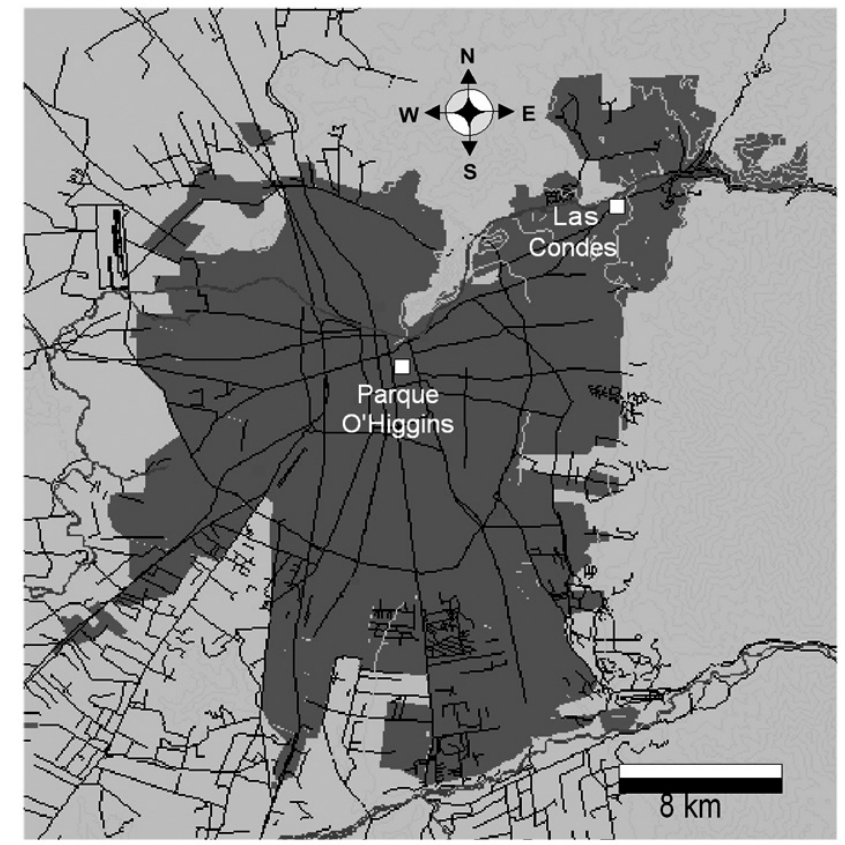

Figure 1. Map of Santiago City showing locations of Las Condes and Parque O'Higgins

Ozone forecasting episodes was obtained using the daily maximum temperature. The experimentally measured values (maximum daily 8 hours average ozone concentrations and maximum daily temperature) were plotted in graphical ozone vs. T plot. The field of the plot was divided in four sub fields by two lines, one parallel to the $\mathrm{X}$ axis located at $120 \mu \mathrm{g} \mathrm{m}^{-3}$ and other parallel to the $y$ axis located at the critical temperature.



The numbers of the points in each field correspond to:

B: correct prediction of days with episodes

C: correct prediction of days without episodes

A: false negative

D: false positive

Linear regression and multi parametric analysis considering 8 hours average ozone concentration and temperature, location and month of year, as independent variable [Ozone $]=\mathrm{a}+\mathrm{b}[\mathrm{X}]$; $\mathrm{a}$ and $\mathrm{b}$ was determined using Origin 7.0, a Scientific Graphing and Analysis Software.

\section{RESULTS AND DISCUSSION}

Relevant points that must be considered in an evaluation of ozone levels in Santiago are:

1. Why ozone levels positively correlate with the maximum daily temperature?

2. Why ozone levels are higher in Las Condes than downtown? ${ }^{23}$

3. Why ozone levels are higher in weekends? ${ }^{24}$
III.1 Ozone levels and maximum daily temperature

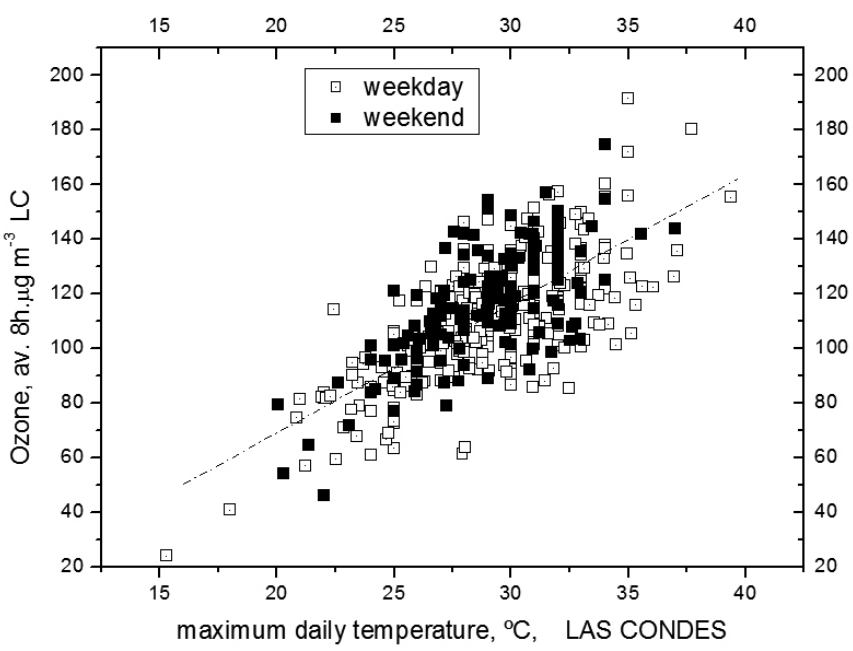

Figure 2. Lineal relationship between 8 hours average ozone and daily maximum temperature obtained in Las Condes. $\square$ Weekend $\square$ Weekday [ozone] $=\mathrm{a}+\mathrm{b}[\mathrm{T}] \quad(\mathrm{a}=-25.42 \pm 6.44 ; \mathrm{b}=4.77 \pm 0.22 ; \mathrm{r}=0.707 ; \mathrm{N}=472 ; \mathrm{p}<$ 0.0001 )

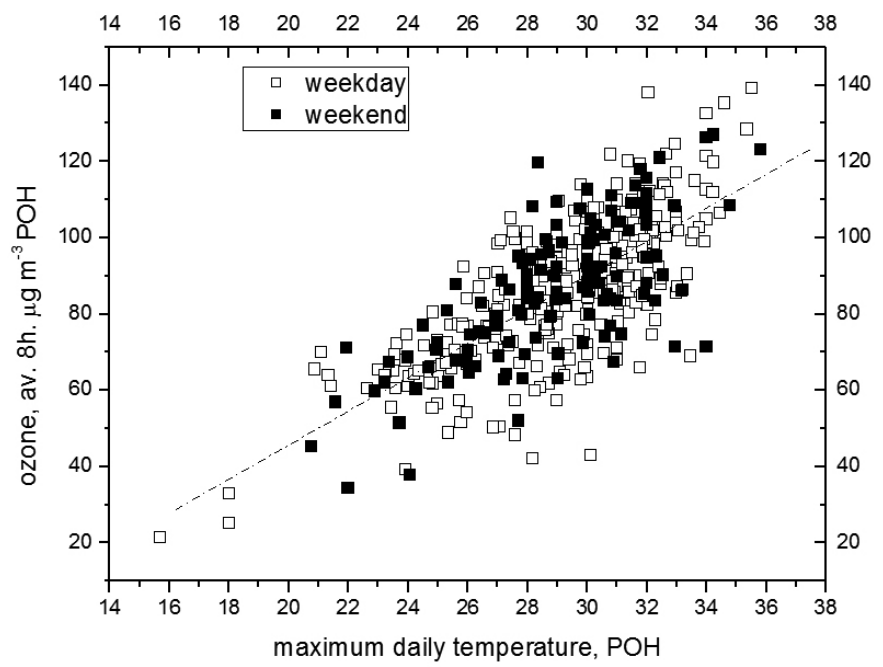

Figure 3. Lineal relationship between average 8 hours ozone and daily maximum temperature obtained in Parque O'Higgins. $\square$ Weekend $\square$ Weekday [ozone] $=\mathrm{a}+\mathrm{b}[\mathrm{T}](\mathrm{a}=-46.51 \pm 5.58 ; \mathrm{b}=4.57 \pm 0.19 ; \mathrm{r}=0.755 ; \mathrm{N}=$ 434; $p<0.0001)$

Figures 2 and 3 show data obtained at LC, Fig 2 and POH, Fig 3. These data show a positive correlation between maximum daily temperature and maximum ozone concentrations. If it is assumed a lineal relation the Eqns. derived at both sampling sites, expressed in $\mu \mathrm{g} \mathrm{m}^{-3}$, were

$$
\begin{aligned}
& \text { Las Condes: } \left.\text { [Ozone }_{8 \mathrm{~h}}\right]=-25.43 \pm 6.4+4.78 \pm 0.22 \mathrm{~T}_{\max } \\
& \text { Parque O'Higgins: } \left.\text { Ozone }_{8 \mathrm{~h}}\right]^{\prime}=-43.21 \pm 6.9+4.44 \pm 0.23 \mathrm{~T}_{\max } \text { in } \mathrm{POH}
\end{aligned}
$$

Im et al. ${ }^{20}$ reported that in cities in the Eastern Mediterranean ozone mixing ratios increase almost linearly with temperature with a rate of increase of $2 \mu \mathrm{g}$ $\mathrm{m}^{-3}{ }^{\circ} \mathrm{K}^{-1}$ in all places considered but Istanbul, where the slope was only 0.8 $\mu \mathrm{g} \mathrm{m}^{-3} \mathrm{~K}^{-1}$. It is remarkable that, in Santiago de Chile, we have found rates of changes in ozone concentrations higher than $4 \mu \mathrm{g} \mathrm{m}^{-3} \mathrm{~K}^{-1}$ in LC. These values would indicate that the ozone concentrations in Santiago are particularly sensitive to the ground temperature. Jorquera et al. ${ }^{5,6}$ have proposed that the strong dependence of ozone levels on maximum air temperature is that this is a good surrogate for incoming radiation and mixing heights, main parameters 
that should control the urban ozone concentration. In fact, the particular micrometeorology of Santiago associate low mixes heights in the morning to high early afternoon temperatures. ${ }^{23}$

Another factor that can relate high temperatures and high ozone levels is an increase in the VOC/NOx ratio in days of high temperature, due to an increase in hydrocarbons evaporation and biogenic emissions. In particular, it has been observed that biogenic contribution to VOCs in Santiago is maximal at the hours of highest temperatures. ${ }^{24}$ Furthermore, it must be noted the possible feedback between temperature and ozone levels. In fact, increased temperature can increase the ozone levels, increasing so the green-house effect and further increasing the temperature. Dueñas et al. ${ }^{16}$ proposes a kinetic explanation stating that temperature plays an enhancing role in the propagation rate of the radical chains taking place in photochemical smog and an opposite effect on the termination rates of these chains.

It is interesting to note that the relationship between temperature and ozone could be a two-ways road. In fact Beaney and Gough ${ }^{27}$ have discussed the influence of tropospheric ozone on the air temperature of the city of Toronto, Canada. (Green house effect).

III.2 Ozone levels in Las Condes (Eastern city outskirts) and Parque O'Higgins (downtown)

A comparison of the data presented in Figs. 2 and 3 show that ozone values at Las Condes station are considerably higher than downtown and high ozone events are most frequent in the city outskirts. This has been traditionally associated to the transport of oxidized air masses from downtown to the Eastern locations during early afternoon. ${ }^{23}$ However, it is frequent to observe higher temperatures in Las Condes, (Figure 4) a phenomenon that could explain "per se", at least partially, the occurrence of high ozone concentrations in the East part of the city where emissions of particles and ozone precursors are considerably reduced. This reduction could decrease the amount of particulate material (reducing reflected solar radiation) increasing so the air temperature and the incoming solar radiation at ground level. Furthermore, it must be taken into account the above mentioned synergism between temperature and ozone that can increase their concentrations beyond those expected from the mere transport of oxidized air masses.



Figure 4. Difference between the maximum daily temperatures in Las Condes and Parque O'Higgins plotted as a function of the maximum temperature in Las Condes.

Figure 4 show that, particularly for days of high temperature, maximum temperature at Las Condes surpass those observed downtown. In order to establish if this difference can explain the occurrence of events in Las Condes, we applied a multiparametric treatment to the data employing ozone concentrations as dependent parameter, and the temperature and location as independent variables. The results obtained are shown in Table 1.
Table 1. Comparison of ozone concentrations in Las Condes and Parque $\mathrm{O}$ 'Higgins beyond possible temperature differences. $\left(\mu \mathrm{g} \mathrm{m}^{-3}\right)$.

\begin{tabular}{|c|c|c|}
\hline PARAMETER & COEFFICIENT & PROBABILITY \\
\hline Y-Intercept & $-75.62 \pm 4.54$ & $<0.0001$ \\
\hline Temperature & $4.65 \pm 0.15$ & $<0.0001$ \\
\hline Location & $26.90 \pm 0.92$ & $<0.0001$ \\
\hline
\end{tabular}

Dependent variable: ozone $2:$ LC)

Independent variables: maximum daily temperature. Location (1: $\mathrm{POH}$;

Equation: $\quad$ Ozone $=\mathrm{Y}+\mathrm{a}_{\mathrm{T}} \mathrm{T}+\mathrm{b}_{\mathrm{loc}}$ Loc

The results presented in Table 1, show that the location establishes a noticeable difference in the predicted ozone values that is not related to possible differences in temperature. In particular, since this parameter assigned to the location range between 1 and 2, the data would indicate that in days of similar temperature ozone values would be near $27 \mu \mathrm{g} \mathrm{m}^{-3}$ or $13.4 \mathrm{ppb}$ higher in $\mathrm{LC}$ than in $\mathrm{POH}$, a difference attributable to the presence of highly polluted aged masses of air coming from downtown towards LC. These data do not fulfill criteria ii) and both sets of data require different critical temperatures to allow predictions of ozone episodes.

\section{III.3 Ozone concentrations over the whole summer periods.}

In order to asses if similar parameters conditioned ozone concentrations over all summer period, we apply a multi parametric regression with the month and temperature as independent parameter. The results are included in the Table 2

The data collected in Table 2, indicate that, at both seasons, there is a significant difference in the values obtained at different months. Since the coefficients of the regression are negative and we have assigned a higher value (2.0) to the hottest months (January and February) the data would indicate that, independently of temperature, the ozone levels in December and March are ca. $4.7 \mu \mathrm{g} \mathrm{m}^{-3}$ higher. However, the effect of the month is not large enough as to deserve a different procedure to predict ozone levels along different summer periods and the data collected during the four months can be considered together. These data then reasonably fulfils criteria iii).

Table 2. Comparison of ozone values measured during different summer months beyond effects of differences in temperature.

\begin{tabular}{|c|c|c|}
\hline PARAMETER & POH & LC \\
\hline \multirow{2}{*}{ Y-Intercept } & $-42.9 \pm 5.3$ & $-24.5 \pm 6.3$ \\
& $\mathrm{p}<0.0001$ & $\mathrm{p}<0.0001$ \\
\hline \multirow{2}{*}{ Temperature } & $4.8 \pm 0.18$ & $4.98 \pm 0.27$ \\
& $\mathrm{p}<0.0001$ & $\mathrm{p}<0.0001$ \\
\hline \multirow{2}{*}{ Month } & $-7.57 \pm 1.13$ & $-4.71 \pm 1.5$ \\
& $\mathrm{p}<0.0001$ & $\mathrm{p}<0.0001$ \\
\hline
\end{tabular}

Dependent variable: ozone

Independent variables: maximum daily temperature. Month (1: December and March; 2 : January and February

Equation : Ozone $=\mathrm{Y}+\mathrm{a}_{\mathrm{T}} \mathrm{T}+\mathrm{b}_{\text {month }}$ Month

\section{4. Ozone levels in weekend}

Maximum ozone concentrations ( 8 hours mobile average) in weekdays and weekend are similar (Figures 2 and Figure 3). With respect to ozone levels during weekends in Santiago, there seems to be two conflicting sets of results. By one side, Jorquera et al. ${ }^{6}$ and Seguel et al..$^{24}$ sustain that ozone concentrations are higher during weekends despite lower concentrations of ozone precursors, a phenomenon known as "weekend effect". On the other hand, Rubio et al. ${ }^{28,29}$ has proposed that this effect is moderated and produces similar concentrations in weekends and weekdays.

One of the relevant observations arising from Jorquera group is that ozone in weekends behaves differently at downtown locations. In particular their concentrations on weekends are higher than on workdays, a result explained in terms of reduced $\mathrm{NO}$ emissions that could reduce ozone removal. This proposal 
is consistent with an analysis of the effect of NOx emission reduction on ozone levels ${ }^{30}$. Furthermore reduced (and later) emissions could reduce the amount of particulate matter in weekends. This could increase the temperature and the intensity of ground level radiation, increasing so diurnal ozone concentrations. In this context, it is interesting to note that when temperature and weekday/ weekend days are considered as independent parameters, disappears (or is substantially reduced) the contribution of the type of day, ${ }^{29}$ indicating that the reported effect is a surrogate of the increase temperature in weekends (Table 1). Temperature as an only predictor of ozone episodes satisfies then criteria iv). The higher (average) temperatures observed in weekends explains the apparently conflicting conclusions reported for Santiago since Jorquera et al. ${ }^{6}$ and Seguel et al..$^{24}$ compare average values of ozone levels obtained in weekends and weekdays, while Rubio et al. ${ }^{29}$ compare values obtained measured in days of similar temperature. Data obtained in weekends and weekdays fulfils criteria iv), particularly in LC.

III. 5. Forecasting of ozone episodes base on predicted maximum temperatures.

The above discussion shows that different parameters must be employed in $\mathrm{LC}$ and $\mathrm{POH}$ to predict ozone episodes. The quality of these predictions, based on the data are given in Figures 5 and 6, is shown in Table 3 for LC.

Table 3. Quality of ozone forecasting based on the daily maximum temperature as unique predictor.

\begin{tabular}{|c|c|c|}
\hline LOCATION & LC & POH \\
\hline Critical Temperature & $30^{\circ} \mathrm{C}$ & $32.5^{\circ} \mathrm{C}$ \\
\hline Days considered & 561 & 550 \\
Ozone episodes & 171 & 12 \\
\hline Predicted Episodes & $114(67) \%$ & $10(84 \%)$ \\
False negative** & $57(33 \%)$ & \\
\hline & & $30(25 \%)$ \\
\hline False positives* & $77(24 \%)$ & \\
\hline
\end{tabular}

- Corresponds to a false episode prediction (high temperature without ozone event)

- $\quad * *$ Ozone episode with low temperature (false negative)



Figure 5. Plot of maximum ozone concentrations ( 8 hours mobile average) in Las Condes and maximum daily temperatures. The horizontal line shows the air quality standard and the vertical line corresponds to the critical temperature of $30^{\circ} \mathrm{C}$

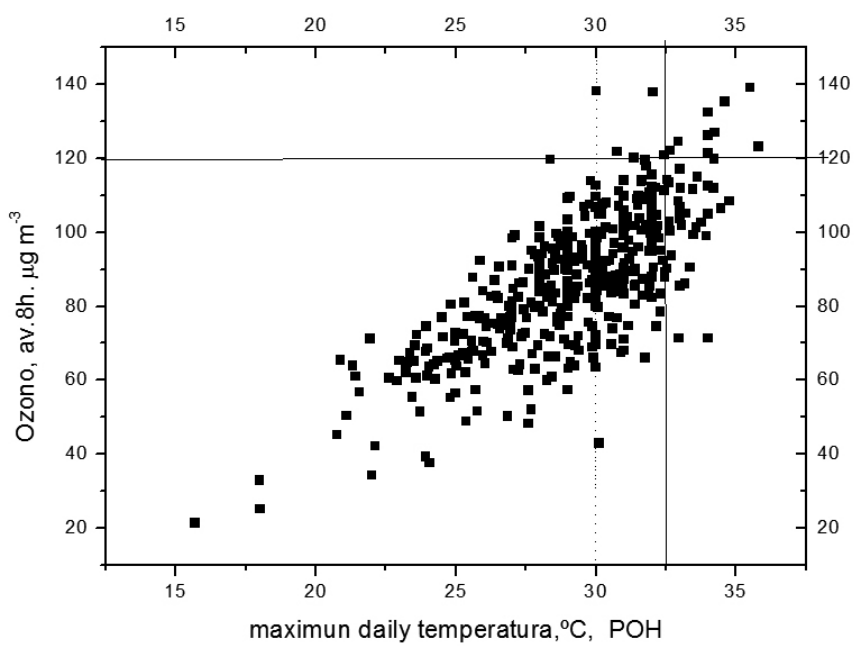

Figure 6. Plot of maximum ozone concentrations ( 8 hours mobile average) in Parque O'Higgins and maximum daily temperatures. The horizontal line shows the air quality standard and the vertical line corresponds to the critical this temperature $32.5^{\circ} \mathrm{C}$

The data of Table 3 show that in Las Condes, of the 171 episodes, 114 of them took place in days whose maximum temperature was higher than $30^{\circ} \mathrm{C}$. Furthermore, it is interesting to note that ozone concentration was always below to $150 \mu \mathrm{g} \mathrm{m}^{-3}$ when this critical temperature is not surpassed. The limiting temperature was selected to maximize the quality of the prediction.

In fact, the most dangerous errors are the false negatives. These correspond to episodes not forecast by the proposed rule (i.e. ozone episodes in which the temperature remains below $30^{\circ} \mathrm{C}$.) The data of table 3 show that $2 / 3$ of ozone episodes occur in LC en days whose temperature surpasses the $30{ }^{\mathrm{a}} \mathrm{C}$ limit. This would imply a significant predicting capacity of the proposed rule. In fact, taking events and no events the capacity of the model to predict the ozone out coming of the present and subsequent days from the weather forecast is of nearly $76 \%$.

Although the number of episodes in $\mathrm{POH}$ is very small to allow a meaningful discussion of the results the "model" correctly predicts 10 of the 12 episodes and the proportion of false negatives is very small

\section{CONCLUSIONS}

In the urban air of Santiago there exist a fair correlation between the daily maximum temperature and the probability of episodes of high ozone concentrations. This implies that this single parameter can be employed as a predictor of the risk of carrying out outdoors activities accessible to the common citizen and based on the daily weather forecast. This is particularly important in Santiago's eastern outskirts where ozone episodes take place when the maximum temperature surpasses $30{ }^{\circ} \mathrm{C}$ in summer in weekdays and weekends, irrespective of the month.

\section{ACKNOWLEDGEMENTS}

This work has been supported by FONDECYT 1120366, and CEDENNA

\section{REFERENCES}

1.- B. Finlayson-Pitts and J. Pitts Chemistry of the upper and lower atmosphere. Ed. Academic Press, 2000.

2.- M. A. Rubio, E. Lissi, G. Villena, V. Caroca, E Gramsch and A. Ruiz. J. Chil. Chem. Soc. 50, 2, 375-379 (2005).

3.- www.asrm.cl

4.- M.A. Barrero, J.O.Grimalt and L. Canton, Chemometrics and intelligent laboratory systems. 80, 67-76, (2006)

5.- H. Jorquera, R. Pérez, A. Cipriano, A. Espejo, M.V. Letelier and G. Acuña, Atmos Environ. 32, 3415-3424, (1998).

6.- H. Jorquera, W. Palma, J. Tapia, Atmos. Environ. 34, 4073-4084, (2000). 
7.- O.R. Sanchez-Ccoyllo, R.Y.Ynoue, L.D. Martins, F. De Andrade, Atmos. Environ. 40, 552-562, (2006)

8.- J. Dawson, P.J. Adams, S.N. Pandis, Atmos. Environ. 41, 1494-1511, (2007)

9.- Khatibi R., Naghipour L., Ghorbani M.A., Smith M.S., Karimi V., Farhoudi R., Delafrouz H., Arvanaghi H. Atmos. Environ. 68, 286-294, (2013).

10.- M.I. Khoder, Environ. Monitor Assess. 149, 349-362, (2009)

11.- D.M. Markovic, D.A. Markovic, J. Serbian Chem. Soc. 70,1487-1495. (2005)

12.- O.A. Tarasova, A.Y. Karpetchko, Atmos. Chem. Phys. 3, 941-949, (2003)

13.- M. Khiem, R. Ooka, H. Huang, Advances in Meteorology. 13 doi:10.1155/2010/349248, (2010).

14.- F.M. Vukovich, J. Sherwell, Atmos. Environ. 37, 971-981, (2003).

15.- S.A. Abdul.Wahab, S.M. Al-Alawi, Environmental Modeling and Software. 17, 219-228, (2002).

16.- E. Stathopoulou, G. Mihalakakou, M. Santamouris, H.S. Bagiorgas, $J$. Earth Syst. Sci. 117, 227-236, (2008).

17.- Y.C. Lee, M. Wening, X. Yang X. Air Quality Atmos. Health. 2, 111-121, (2009)

18.- C. Dueñas, M. C. Fernandez, S. Cañete, J. Carretero, E. Liger, The Sci. of the Total Environ. 299, 97-113, (2002)

19.- D.J. Rasmussen, A.M. Fiore, V. Naik, L.W. Horowitz, S. J. McGinnis, M.G. Schultz, Atmos. Environ. 47, 142-153, (2012).
20.- U. Im, K. Markakis, A. Poupkou, D. Melas, A. Unal, E. Gerasopoulos, N. Daskalakis, T. Kindap, M. Kanakidou, Atmos. Chem. Phys. 11, $3847-$ 3864, (2011).

21.- J. Biswas, K. John, Z.M. Farooqui, Proceeding (2008).

22.- C.A. Cardelino, W.L. Chameides, J. Geophys. Res. Atmos. 95, 1397113979, (1990).

23.- H. Romero, M. Ihl, A. Rivera, P. Zalazar, P. Azocar, Atmos. Environ. 33, 4039-4047, (1999)

24.- R. Seguel, R.G. Morales, M.A. Leiva., Environmental Pollution. 162, $72-79,(2012)$

25.- J. Rutllant, R. Garreaud, Environ. Monitoring Assess. 34, 223-244, (1995).

26.- B. Rappengluek, R. Schmitz, M. Bauerfeind, F. Cereceda-Balic, D. von Baer, H. Jorquera, Y. Silva, P. Oyola, . Atmos. Environ. 39, 2913-2931, (2005).

27.- G. Beaney, W.A. Gough, . Atmos Environ. 36, 2319-2325, (2002).

28.- M.A. Rubio, P. Oyola, E. Gramsch, E. Lissi, J. Pizarro, Villena, Atmos Environ. 38, 4931-4939, (2004).

29.- M.A. Rubio, K. Sánchez, E. Lissi. J. Chil. Chem. Soc. 56, 709-711, (2011)

30.- Y. Y. Elshorbany, J. Kleffmann, R: Kurtenbach, M.A. Rubio, E. Lissi, G. Villen, E. Gramsch, A.R. Rickard, M.J. Pilling, P. Wiesen, Atmos. Environ. 43, 6398-6407, (2009). 